\title{
Experiencias
}

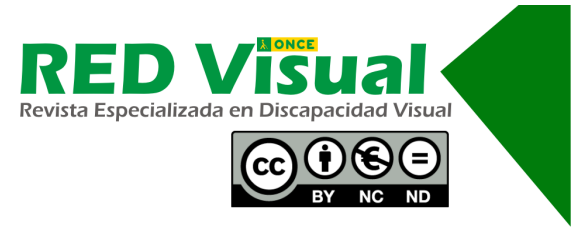

\section{Adaptación del bastón de movilidad en un caso de sordoceguera y movilidad reducida dentro del Programa de Rehabilitación de la $\mathrm{ONCE}^{1}$}

\author{
Mobility cane adaptation to deafblindness and impaired mobility \\ in an ONCE rehabilitation programme
}

\section{E. Galván González}

\section{Resumen}

La experiencia que se presenta surge de la necesidad planteada por una afiliada con sordoceguera y con movilidad reducida (en silla de ruedas eléctrica) de poder salir sola a la calle. El objetivo fundamental marcado ha sido conseguir la autonomía en los desplazamientos por entornos exteriores conocidos. Para ello, y tras un proceso de ensayo-error, se adapta el bastón de movilidad para su uso y manejo con la silla de ruedas eléctrica, creando un material con el que la usuaria puede obtener la seguridad necesaria, consiguiendo con ello lo propuesto al iniciar este programa de Orientación y Movilidad (OyM). El uso del material creado se puede generalizar a otros grupos de personas con discapacidad visual, ya que tiene múltiples usos (se puede realizar en distintas medidas, en diferentes circunstancias del usuario, en múltiples entornos...).

\section{Palabras clave}

Discapacidad visual. Sordoceguera. Rehabilitación. Orientación y movilidad. Autonomía. Bastón de movilidad. Silla de ruedas eléctrica.

\footnotetext{
1 Trabajo galardonado con uno de los accésits del IV Concurso de Experiencias de Innovación y Buenas Prácticas en Servicios Sociales de la ONCE, presentado con el título $A$ ruedas.

Galván, E. (2020). Adaptación del bastón de movilidad en un caso de sordoceguera y movilidad reducida dentro del Programa de Rehabilitación de la ONCE. RED Visual: Revista Especializada en Discapacidad Visual, 76, 91-114. https://doi.org/10.53094/IXVR2685.
} 


\begin{abstract}
The experience described arose around the need expressed by a deafblind ONCE member with impaired mobility (electric wheelchair-bound) for independent outdoor travel. The primary goal was to enable her to move about independently in familiar outdoor environments. After a process based on trial and error, a mobility cane was adapted for use with her electric wheelchair. As the resource created ensured sufficient user safety, the objective proposed at the outset of this orientation and mobility (O\&M) programme was deemed to be met. Resource use may be extended to other groups of people with visual disability, for it is apt for a number of purposes (it can be made with different measurements for different user circumstances in different environs...).
\end{abstract}

\title{
Key words
}

Visual impairment. Deafblindness. Rehabilitation. Orientation and mobility. Independence. Mobility cane. Electric wheelchair.

\section{Presentación y justificación}

«Quien salta puede caer, pero también es posible que vuele. Es el momento de saltar». Réquiem, Lauren Oliver (2013)

Nunca se tiene la certeza de que algo va a salir bien o mal, pero si se piensa que existe una mínima posibilidad de conseguirlo, hay que intentarlo.

Cuando se comienza por primera vez a trabajar con un afiliado o afiliada a la ONCE se tiene bastante información del caso en concreto. Normalmente la formación recibida, la bibliografía consultada, la experiencia - aunque sea pequeña...-, todo ayuda a poder llevar a cabo un plan individual y adecuado a cualquier circunstancia que pueda presentarse. Pero hay veces que esas situaciones se «salen» de lo normalmente establecido.

En esos casos hay que hacerse preguntas como: ¿hasta dónde se puede llegar?, ¿podría hacerse algo más?, ¿es justo no intentarlo?

Todos los afiliados tienen derecho a recibir la mejor atención posible, el mayor aprendizaje, todo el esfuerzo, apoyo y ayuda para satisfacer, o al menos intentar, la

Galván, E. (2020). Adaptación del bastón de movilidad en un caso de sordoceguera y movilidad reducida dentro del Programa de Rehabilitación de la ONCE. RED Visual: Revista Especializada en Discapacidad Visual, 76, 91-114. https://doi.org/10.53094/IXVR2685. 
consecución positiva de sus demandas, aunque sea en condiciones muy complicadas, aunque existan factores muy problemáticos y otras discapacidades añadidas... Podría decirse que más aún en esos casos, ya que son los que más necesitan una mejora en su vida.

Así, el haber conseguido un cambio en la vida de una afiliada, sordociega, con importante discapacidad física, es lo que motiva este intento de difusión para ser tenido en cuenta como ayuda y estímulo para la actuación ante la posibilidad de algún caso similar.

Se trata de una afiliada de 50 años de edad, vecina de una localidad muy alejada de su centro de referencia de la ONCE, que denominaremos, de cara a garantizar su anonimato, Lucía. Es afiliada desde 2002 y tiene también reconocida la sordoceguera desde 2014, padeciendo además el síndrome de Charcot-Marie-Tooth, lo que hace que, físicamente, tenga afectados, a día de hoy, los miembros inferiores, por lo que se desplaza en silla de ruedas.

El diagnóstico de la usuaria en cuestión es síndrome de Usher tipo II A (retinosis pigmentaria y sordera), conservando un campo visual menor de 10 grados (menos del $10 \%$ ) y una agudeza visual de 0,3 (el 30\%). En el ámbito de la sordoceguera, la funcionalidad auditiva que se le asignó cuando pasó su reconocimiento fue que «entiende con dificultad, pero habla».

La trabajadora social del equipo detectó la necesidad en Lucía de «mejorar su vida». Llevaba tres años sin salir sola de casa y deseaba poder llevar a cabo, de forma autónoma, algún itinerario en exteriores próximos a su domicilio, haciendo uso de su silla de ruedas eléctrica. De inmediato se contactó con ella para tratar de conseguir lo que demandaba.

En la búsqueda de bibliografía previa al trabajo para ver metodologías y resultados que se hubieran dado previamente para tratar de conseguir el objetivo, solo se hallaron trabajos documentados de movilidad con personas con discapacidad visual en silla de ruedas en desplazamientos de interiores, sin encontrar ningún auxiliar de movilidad para ellos.

Fue entonces cuando hubo que pensar, idear y madurar la idea de una ayuda que resolviera los problemas a los que se enfrentaba la afiliada para salir sola: cómo

Galván, E. (2020). Adaptación del bastón de movilidad en un caso de sordoceguera y movilidad reducida dentro del Programa de Rehabilitación de la ONCE. RED Visual: Revista Especializada en Discapacidad Visual, 76, 91-114. https://doi.org/10.53094/IXVR2685. 
conseguir que Lucía fuera autónoma en exteriores cercanos y cómo comenzar a intentarlo. Era necesaria la existencia de un material que le posibilitara un desplazamiento seguro en un entorno exterior, cercano y conocido.

\section{Objetivos}

El objetivo prioritario de este proyecto es conseguir la autonomía de Lucía. Es un programa centrado en la Orientación y la Movilidad, buscando un auxiliar lo más adecuado posible, ya que ella sola con su silla de ruedas llevaba más de tres años sin poder salir a la calle.

Se necesitaba encontrar algo que permitiese una movilidad autónoma, anticipando los obstáculos a una distancia adecuada para que los desplazamientos fuesen seguros.

Se marca como objetivo, pues, dar una solución viable a la demanda de la afiliada en cuanto a trabajar de forma autónoma recorridos habituales de su entorno conocido, valorando posibilidades para poder realizarlos de forma segura.

Del mismo modo, para conseguir este objetivo, se engloban objetivos más específicos a trabajar, como bordear obstáculos con la silla (alcorques, postes, bolardos...), ser capaz de seguir la pared, analizar el tráfico para realizar con seguridad cruces simples y con semáforo...

\section{Población destinataria de la experiencia}

La experiencia se ha realizado con una afiliada, tal y como se ha expuesto anteriormente, con síndrome de Usher tipo II A (retinosis pigmentaria y sordera) con discapacidad motora añadida (síndrome de Charcot-Marie-Tooth), por lo que se desplaza en silla de ruedas eléctrica.

Dentro de la experiencia realizada se ha conseguido crear un material para la consecución de los objetivos propuestos, por lo que, aunque la experiencia sea para una persona con discapacidad visual que se desplaza en silla de ruedas, el uso del material creado se puede generalizar a otros grupos de personas con discapacidad visual,

Galván, E. (2020). Adaptación del bastón de movilidad en un caso de sordoceguera y movilidad reducida dentro del Programa de Rehabilitación de la ONCE. RED Visual: Revista Especializada en Discapacidad Visual, 76, 91-114. https://doi.org/10.53094/IXVR2685. 
ya que tiene múltiples usos (se puede realizar de distintas medidas, para diferentes circunstancias del usuario, en múltiples entornos...).

\section{Temporalización y fechas de realización}

Este proyecto se llevó a cabo desde octubre de 2018 hasta junio de 2019, siendo las fechas reales de atención desde el 18 de enero hasta el 23 de mayo de 2019.

La solicitud de demanda, como se explicará con detalle más adelante, llegó en octubre de 2018 y, tras varias citas pospuestas por problemas de salud de Lucía, se tuvo el primer contacto presencial el 18 de enero de 2019. Durante todo este tiempo se ha estado trabajando y evolucionando en su autonomía, hasta conseguirlo de forma segura y finalizar las visitas el 23 de mayo de 2019.

\section{Metodología}

La metodología que ha marcado todo el trabajo ha sido la de ensayo-error. Esta metodología consiste en probar una alternativa y verificar si funciona. Si es así, se tiene una solución. En caso contrario (resultado erróneo), se intenta una alternativa diferente.

Todo con el objetivo de conseguir la autonomía de la afiliada, de intentar hacerlo, y con la motivación como eje transversal acompañando en todo momento.

Se expone, a continuación, el proceso llevado a cabo para poder reflejar el porqué del camino seguido para llegar al fin deseado.

\subsection{Surge la necesidad en la afiliada}

En la segunda quincena de octubre de 2018 se tiene conocimiento del caso de esta afiliada. Una señora de 50 años, con sordoceguera, con un síndrome que además la obliga a moverse en silla de ruedas eléctrica y que lleva más de tres años sin salir de casa sola. Y ella quiere salir. Desea no depender de los suyos para sus desplazamientos autónomos, aunque solo sea a dar un paseo, algo tan simple y que para ella supondría tanto.

Galván, E. (2020). Adaptación del bastón de movilidad en un caso de sordoceguera y movilidad reducida dentro del Programa de Rehabilitación de la ONCE. RED Visual: Revista Especializada en Discapacidad Visual, 76, 91-114. https://doi.org/10.53094/IXVR2685. 


\subsection{Comienza la tarea...}

Tras comprobar los datos que existen de Lucía en la aplicación, se llevan a cabo los contactos telefónicos, aunque no se realiza el primer encuentro presencial hasta enero debido a sus problemas de salud.

En estos dos meses en los que no puede acudir a una cita presencial ni recibir atención en su entorno surgen muchas dudas:

- ¿Cómo será su visión funcional?

- ¿Sus problemas físicos la dejarán mover bien las manos para hacer un arco con el bastón o le dolerán?

- Y si hace un arco con el bastón, ċe dará en las piernas ya que lo va a utilizar sentada?

- ¿Podrá existir algún auxiliar de movilidad para una persona con discapacidad visual que se desplaza en silla de ruedas en exteriores?

- Y si la silla de ruedas es eléctrica, ¿se moverá tan rápido que no pueda proporcionarle nada que llegue a darle seguridad a la hora de anticipar los obstáculos? ¿Tendría habilidad manual precisa para controlar correcta y rápidamente la velocidad y el frenado de la misma?

La verdad es que las múltiples dudas no podrían despejarse hasta que no se comenzara el trabajo con ella. Lo que sí estaba claro era que no se podía decir nada con seguridad por teléfono. Si no se iba a verla y se trabajaba dura y creativamente, era imposible decirle que no había nada para ella o que iba a conseguir todo lo que pidiera. Era necesario ir e intentarlo, por Lucía, por los profesionales y por todos los demás que, si lo conseguía, se podrían ver a su vez beneficiados en un futuro.

La idea era llevar bastones de varias medidas, los cuales no iban a tener la altura que normalmente se utiliza, ya que ella iba a estar sentada.

Pero... ¿y si se le cansaba la mano? Se había buscado bastante información sobre el síndrome de la afiliada, y estaba en silla de ruedas porque tenía problemas motóricos

Galván, E. (2020). Adaptación del bastón de movilidad en un caso de sordoceguera y movilidad reducida dentro del Programa de Rehabilitación de la ONCE. RED Visual: Revista Especializada en Discapacidad Visual, 76, 91-114. https://doi.org/10.53094/IXVR2685. 
que afectaban no solo a las piernas. Podía cansársele la mano al hacer el arco, o chocarle contra las piernas a la hora de mover el bastón y dolerle.

Por todo lo anterior, buscando en Internet, se tuvo en cuenta que la barra en forma de T del catálogo del Centro de Tiflotecnología e Innovación de la ONCE (CTI) podría servir (Figura 1).

Figura 1. Barra en forma de T del CTI

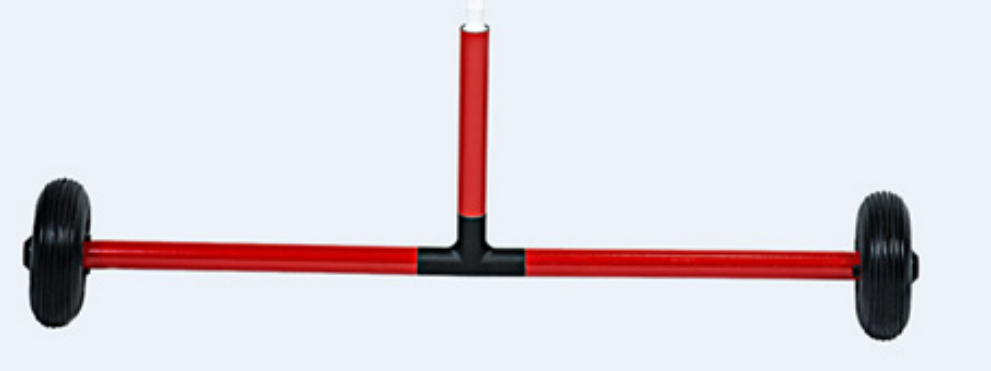

La explicación que acompaña a la foto en la página del CTI es: «Barra en forma de $\mathrm{T}$, resistente y ligera, fabricada en fibra de vidrio en cuyos extremos hay dos pequeñas ruedas, y que se puede acoplar fácilmente a un bastón canadiense a modo de contera».

Este adaptador, de $47 \mathrm{~cm}$ de longitud, resulta de utilidad para aquellas personas con dificultades motrices que no pueden hacer un uso normalizado del bastón de movilidad; es decir, cuando no se puede realizar un arco que garantice la seguridad (personas mayores, con problemas físicos...).

Asimismo, se puede utilizar como prebastón por parte de los niños, como un anticipador de obstáculos que permite mantener la posición correcta del brazo y la muñeca.

Cabe destacar que los desplazamientos que pueden hacerse con este dispositivo serán en entornos cercanos y conocidos para el usuario.

\subsection{El primer encuentro}

Habían pasado dos meses, tiempo para pensar y preparar ese primer encuentro motivador ante circunstancias tan adversas.

Galván, E. (2020). Adaptación del bastón de movilidad en un caso de sordoceguera y movilidad reducida dentro del Programa de Rehabilitación de la ONCE. RED Visual: Revista Especializada en Discapacidad Visual, 76, 91-114. https://doi.org/10.53094/IXVR2685. 
Se aportaron al inicio bastones de varios tamaños, la barra en forma de T... y toda la motivación posible para acometer la tarea, haciendo uso, para las explicaciones primeras, de su domicilio y su entorno muy próximo.

Lo primero que se pudo comprobar fue que usaba su visión funcional como ayuda, ya que la agudeza visual que tenía era de 0,3 y, aunque el campo visual era bastante reducido (menor de 10 grados), tenía un resto de visión que facilitaba el poder realizar prácticas desde el primer día con los bastones y con la barra.

A su vez, fue tranquilizador poder ver que era ella quien controlaba la silla eléctri$\mathrm{ca}$, es decir, que adecuaba la velocidad a la que quería que fuera la silla, pudiendo, del mismo modo, avanzar con un mando poco a poco, haciendo las paradas que creyera convenientes. Su capacidad manual para el manejo de la silla eléctrica podía permitir intentar utilizar un auxiliar de movilidad que facilitara un desplazamiento seguro.

Se comenzaron las pruebas con bastones cortos. Con una mano, la afiliada tenía que dirigir el mando de la silla (al lado derecho), quedándole solo la mano izquierda para coger el bastón e ir haciendo el arco. Con el bastón de 1,12 anticipaba bien los obstáculos y le daba tiempo a frenar en caso de encontrar algo sin chocar sus piernas con nada. Pero, efectivamente, la mano se le cansaba mucho y, además, cuando movía el bastón de izquierda a derecha para realizar el arco con el mismo, tropezaba la mano del bastón con sus piernas y resultaba muy incómodo.

Por ello, descartamos los bastones cortos y pasamos a probar la barra en forma de T del CTI.

La barra en forma de T parecía una idea genial como alternativa al bastón por los motivos recién explicados y debía probarse con ella. No tendría, de esta forma, que mover la mano, e iba a anticipar los obstáculos que se presentaran de frente a ella con un ancho fijo $(47 \mathrm{~cm})$, correspondiente al ancho de su cuerpo.

Pero... Lucía no debía proteger solo el ancho de su cuerpo. Era preciso tener en cuenta que ese ancho es mayor del habitual, porque se desplazaba en silla de ruedas. Así que se comprobó que no iba segura solo con esos $47 \mathrm{~cm}$, porque la silla podía caer

Galván, E. (2020). Adaptación del bastón de movilidad en un caso de sordoceguera y movilidad reducida dentro del Programa de Rehabilitación de la ONCE. RED Visual: Revista Especializada en Discapacidad Visual, 76, 91-114. https://doi.org/10.53094/IXVR2685. 
en un alcorque que estuviera a la derecha o podía dar con la pared de la izquierda, por ejemplo.

Además, las ruedas eran fijas y la afiliada tenía problemas físicos, de forma que, cuando se iba la barra a la izquierda y tenía que enderezarla para llevarla recta (es decir, moverla un poco hacia la derecha), le costaba mucho, porque no giraban las ruedas, sino que tenía que arrastrarla.

De este modo, y por estos motivos, fue necesario descartar esta barra en concreto en el trabajo con ella.

Las visitas fueron eficaces, ilusionantes, sabiendo que, aunque lo que se iba probando no era la solución segura, la motivación que se tenía iba a hacer que, a fuerza de trabajo y tesón, se diera con la solución tarde o temprano.

\subsection{Reflexiones}

Algo estaba muy claro. La barra era buena idea. Aunque esa en concreto no sirviera en este caso, esa idea estaba muy bien. No se podía descartar del todo. ¿Qué habría que cambiar entonces de la barra para poder comenzar el trabajo de Orientación y Movilidad con la afiliada? Se llegó a dos conclusiones.

- El ancho. El ancho de la barra era de $47 \mathrm{~cm}$, y la silla de la afiliada (tras otro encuentro y mediciones) era de $70 \mathrm{~cm}$. Había parte de la afiliada que quedaba desprotegida con la barra que se probó el primer día, pero si se pudiera hacer más ancha ese problema quedaría resuelto para comenzar a ejecutar el programa de movilidad.

- Las ruedas. Las ruedas eran fijas y le costaba mucho enderezar el bastón cuando se iba a la izquierda o a la derecha, por lo que se necesitaba que las ruedas fueran giratorias para que la mano, o más concretamente la muñeca, la moviera lo menos posible.

Se llevó a cabo una consulta con el Departamento de Administración de la Delegación Territorial por si existía la posibilidad de modificar y adaptar ese material que se comercializaba a través del CTI, que, a su vez, nos informó de que la barra tiene una medida estándar de $47 \mathrm{~cm}$. 


\section{5. ¿Se hace, se intenta...?}

Con las ideas muy claras, pero sin posibilidad de comprarlo o adaptarlo, ¿qué se podía hacer entonces? Intentar realizarlo parecido, pero con las adaptaciones necesarias para que funcionase con Lucía.

En ese momento se hizo necesaria la colaboración de un profesional de una ferretería, quien, al explicarle claramente la situación, asesoró en cuanto a tipo de material, medida... Se necesitaba algo que:

- Cubriera el ancho de la silla: $70 \mathrm{~cm}$ de ancho.

- Tuviera ruedas giratorias (primero se hizo con ruedas de silla de despacho y, más tarde, se repitió el material con mejores ruedas).

- Pesara poco, que el material fuese ligero: PVC.

- Pudiera engancharse de alguna forma al bastón: por ejemplo, a través de un cáncamo.

Con los materiales proporcionados y ya montado, se puede observar el resultado final en la Figura 2.

Figura 2. Adaptador inicial creado: barra más ancha en forma de T con ruedas giratorias

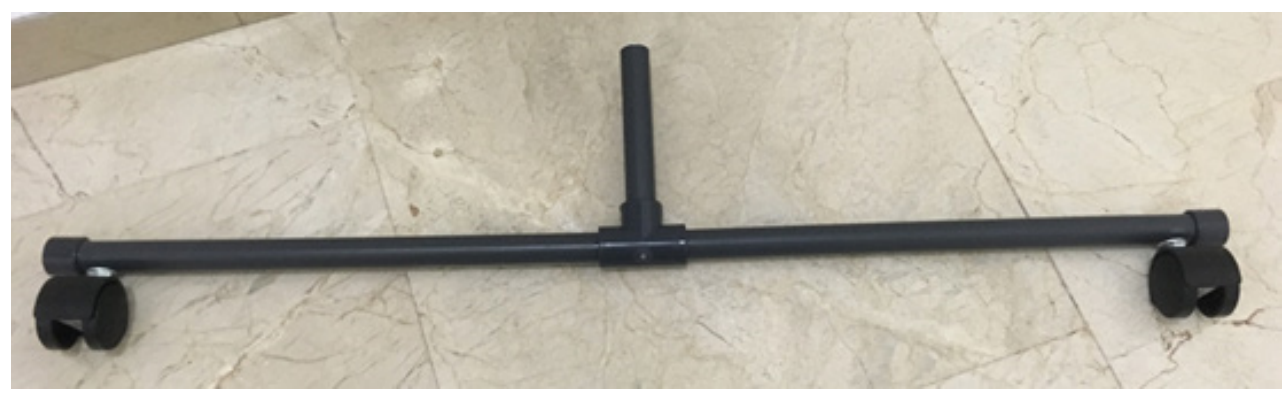

\subsection{Presentación a la afiliada del nuevo instrumento de movilidad}

Se procedió de nuevo a acudir con varios bastones cortos, ya que, aunque la primera vez que se probó el bastón le valió el de 1,12, ahora al colocarlo con este material 
ganaría algo de altura. Fue por eso que se usaron el mismo, uno más corto de 1,07 y uno más largo de 1,17.

Sirviera o no sirviera, se estaba haciendo lo justo para Lucía: intentarlo. Podía dar resultado o, por el contrario, no proporcionar la seguridad necesaria en los desplazamientos y descartarlo como auxiliar de movilidad.

Pero todo el proceso estaba resultando tan motivante que se iba a intentar llegar hasta el final o, al menos, tratar de mejorar su vida, ya que, por poco que fuera el cambio que se llegase a conseguir, habría merecido la pena.

Se probó y el ancho era perfecto. La silla quedaba totalmente cubierta e incluso sobraban $2 \mathrm{~cm}$ de cada lado, por lo que iba a ir bien protegida.

Había que hacer prácticas para ver qué medida de bastón era la adecuada. La duda estaba entre 1,12 y 1,07 sobre todo, pero con el de 1,12 se le cansaba algo la mano, ya que era más largo y le resultaba incómodo. Finalmente, el elegido fue el de 1,07: daba tiempo a encontrar un obstáculo, pudiendo parar la silla totalmente sin tropezar con nada (la elección se hizo tras varias sesiones probando con ambos).

Las prácticas en la calle fueron algo duras al principio. No era solo elegir una medida de bastón, comprobar que el ancho la protegiera y quedar satisfechos con el objetivo cubierto. Se debía entrenar para que los desplazamientos fueran seguros con este instrumento y que realmente Lucía consiguiera ser autónoma en todos los recorridos posibles según sus necesidades, aptitudes e intereses.

Se procedió a la observación, viendo cómo iba, cómo solventaba obstáculos, alcorques, cómo seguía la pared... Pero, a su vez, había que analizar también la accesibilidad del entorno, ya que, al ir en silla de ruedas, eran prioritarias zonas adecuadas de bajada de la acera, ancho mínimo de la misma, estado de la calzada, caminos seguros...

Para ello, el primer día se trabajó el uso del bastón con el nuevo instrumento por su zona muy próxima (Figura 3). Se trata de una acera muy ancha, en buenas condiciones y en una avenida segura con un tráfico constante (pudiendo, a su vez, comprobar si era capaz de oírlo o no, verlo... para tomar referencias a través de todas las vías perceptivas posibles, teniendo en cuenta sus discapacidades).

Galván, E. (2020). Adaptación del bastón de movilidad en un caso de sordoceguera y movilidad reducida dentro del Programa de Rehabilitación de la ONCE. RED Visual: Revista Especializada en Discapacidad Visual, 76, 91-114. https://doi.org/10.53094/IXVR2685. 
Figura 3. Lucía haciendo uso del adaptador en una acera ancha de su pueblo

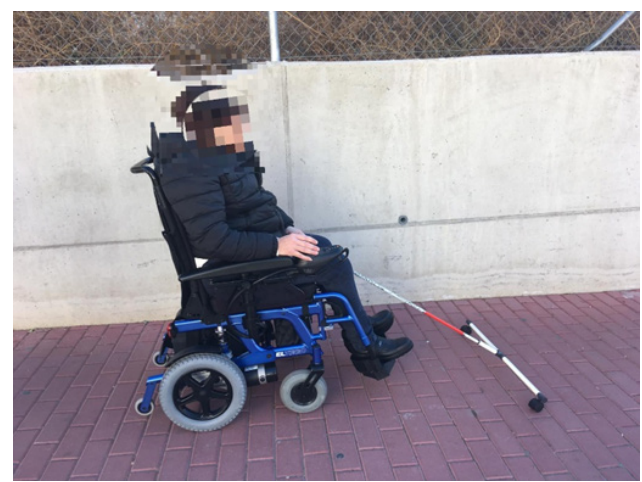

El principio fue un poco tenso; había pasado demasiado tiempo sin salir sola, por lo que la supervisión y el apoyo constante fue muy importante en esta fase. Familiarizarse con el auxiliar de movilidad, con la forma de llevarlo, ir adquiriendo seguridad poco a poco... Se dedicó mucho trabajo al seguimiento de la pared, el ancho de la acera, el qué hacer si se iba a la derecha y dejaba descubierta la parte izquierda, cómo enderezarlo (con las ruedas giratorias ya solo era moverlo sin esfuerzo)... Costó bastante, pero cada vez lo iba haciendo mejor. Tenía que adquirir seguridad y, para ello, con grandes dosis de paciencia, repetición, estrategias correctas para cada situación... poco a poco se comenzaron a conseguir determinados objetivos e ir viendo algunos resultados.

La evolución era muy gratificante, ver cómo cuando había un saliente en un edificio - por ejemplo, en la pared-, no lo veía, pero el bastón le chocaba, y ella paraba la silla mientras ponía el bastón en vertical, el cual quedaba entre sus piernas. Había salvado el obstáculo, no se había dado. Entonces recuperaba la dirección de la marcha dejando atrás ese saliente y continuaba de forma segura hacia el sitio fijado en el ejercicio.

Eso, poco a poco, lo fue integrando, así que se incluyó un aspecto más a trabajar: los alcorques. Si iba en movimiento y se caía el bastón en un alcorque, sabía que tenía que salvar dicho obstáculo. Imaginemos que va por la acera con la pared a la izquierda y el tráfico a la derecha y nota un alcorque a la derecha. Si puede y tiene hueco (aspecto que ella comprobaba), tiene que tratar de salvar dicho obstáculo por el lado izquierdo. Pero podía ocurrir que, una vez ella creyera que había pasado el alcorque, retomara su línea de desplazamiento y aún no lo hubiera pasado (ya que va en silla y tarda más) y pudiera caer una rueda; en este caso, por ejemplo, la trasera derecha en el alcorque, y sufrir una caída. 
Es por esto que fueron necesarios muchos alcorques hasta que controló este obstáculo de maravilla. De este modo, el seguir la pared cuando fuera necesario, el desplazarse por la acera, el pasar alcorques y obstáculos varios de forma autónoma... hizo que Lucía fuese ganando seguridad en el adaptador del bastón, en la calle y en ella misma. Se trabajó también la colocación del bastón con el material a la hora de cruzar pasos de peatones, quedando en vertical mientras aguardaba su momento de cruce, volviendo a la posición normal al retomar la marcha (Figura 4).

Figura 4. Imágenes de la afiliada en recorridos por exteriores con el nuevo auxiliar de movilidad
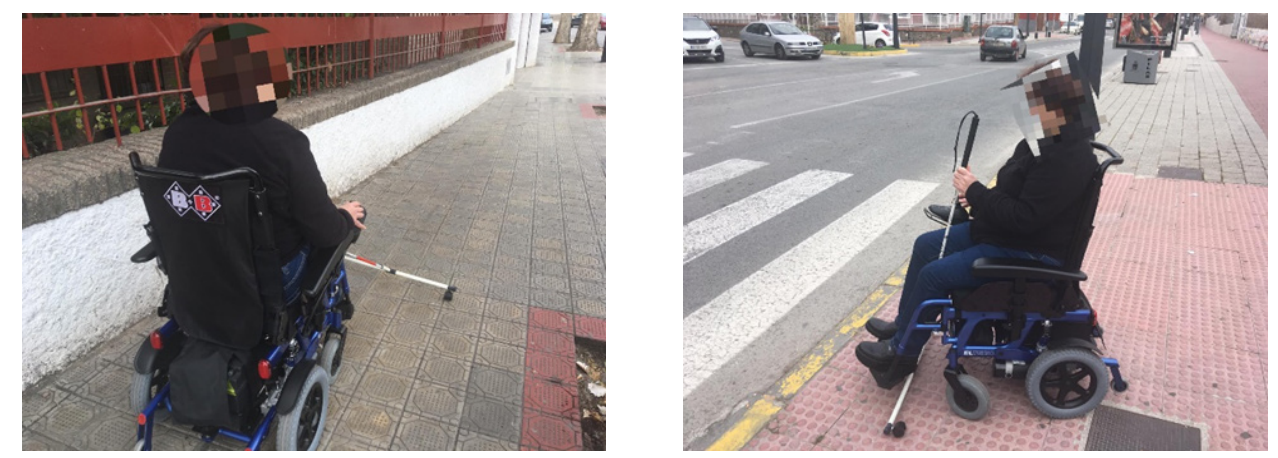

Poco a poco se fueron complicando los espacios, pasando por aceras más estrechas, circulando por zonas con curvas, ángulos, giros... (Figura 5).

Figura 5. Doble imagen de Lucía utilizando el adaptador: a la izquierda por una acera estrecha y a la derecha siguiendo un muro bajo para mantenerse en línea recta
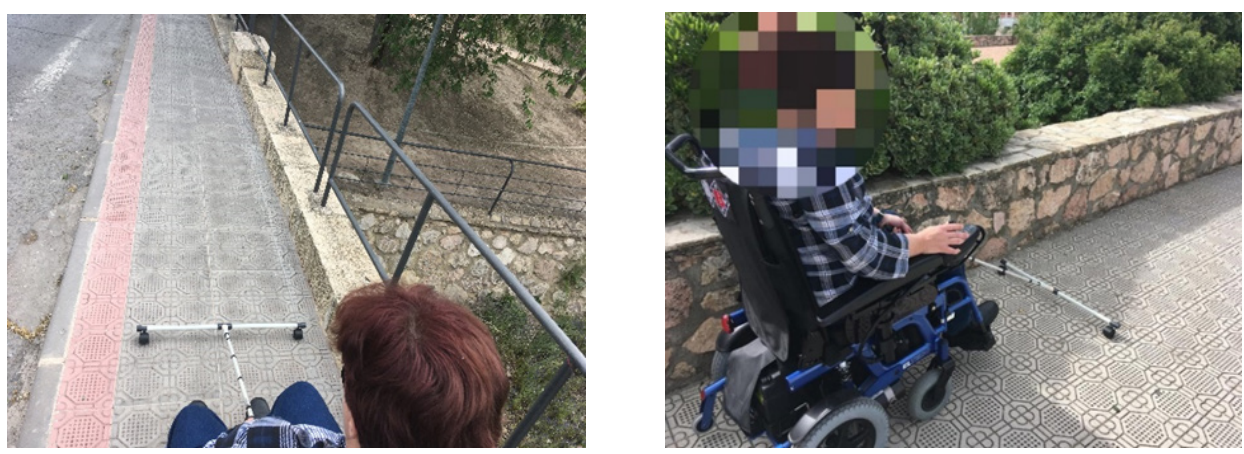

Se comenzaron a trabajar recorridos habituales para ella: al paseo y a la plaza de su pueblo, al centro de salud, a casa de familiares, a supermercados, a sitios donde solía ir con amistades... Recorridos que hasta entonces siempre había hecho acompañada y que, si nadie podía ir con ella, descartaba de su agenda.

Galván, E. (2020). Adaptación del bastón de movilidad en un caso de sordoceguera y movilidad reducida dentro del Programa de Rehabilitación de la ONCE. RED Visual: Revista Especializada en Discapacidad Visual, 76, 91-114. https://doi.org/10.53094/IXVR2685. 
Algunos de los itinerarios fueron más trabajados por la envergadura de los mismos, otros modificados para transitar por zonas más seguras... Pero todos ellos los consiguió realizar.

\subsection{Modificando... se ha logrado}

Una vez dominados los recorridos casi a la perfección, con gran seguridad, de forma totalmente autónoma, mostrando un gran entusiasmo, se procedió a la ampliación de recorridos y zonas con mayor dificultad. Esto trajo consigo la evidencia de que esa adaptación era segura, pero no era lo bastante cómoda como para acometer otros tipos de terreno, otras zonas con mayor dificultad. Funcionaba muy bien, pero quizás las ruedas que se habían utilizado (tipo silla de despacho) eran buenas para recorridos llanos, de interiores, de aceras lisas... pero no lo suficientemente buenas para todos los recorridos que se iban a realizar. Aunque iba muy bien, faltaba algo que mejorase la situación: aún no se había alcanzado un grado de satisfacción total, era posible mejorar.

Se podría decir que las ruedas utilizadas para el material eran como una contera normal, o incluso una contera pequeña para interiores, y Lucía necesitaba algo más parecido a una contera rural para salvar bien los obstáculos y caminar cómodamente sobre el dibujo y relieve que presentaban las aceras que ella transitaba.

Así que se propuso hacer otro adaptador nuevo, pero con ruedas de goma diferentes, para que girasen mejor aún. Nuevamente se solicitó la ayuda de profesionales de la ferretería y se realizó el cambio de las ruedas. En la Figura 6 se puede observar cómo quedó el nuevo y final aparato que iba a servir como auxiliar de movilidad para la afiliada.

Figura 6. Nuevo adaptador con ruedas diferentes a las iniciales

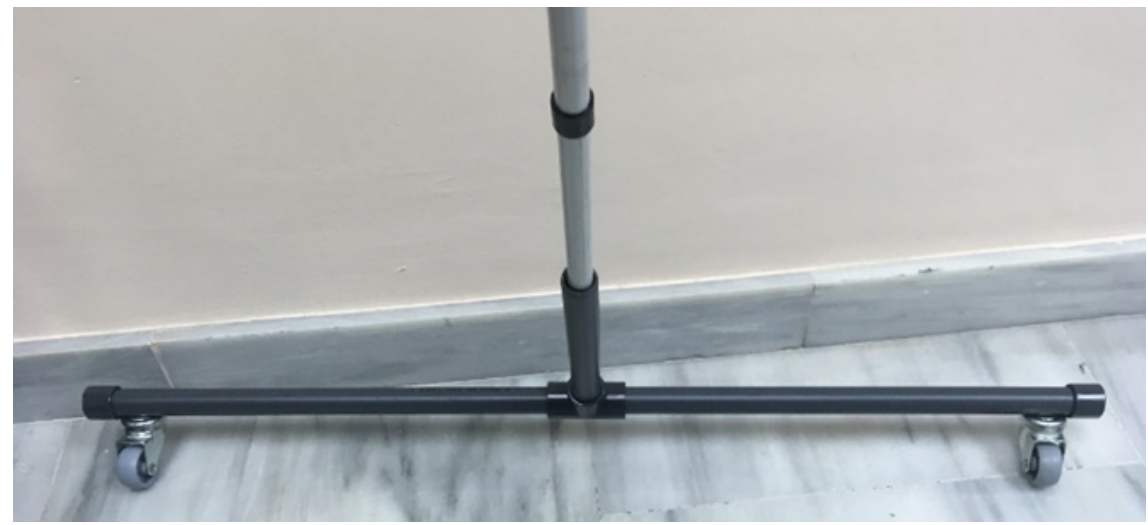

Galván, E. (2020). Adaptación del bastón de movilidad en un caso de sordoceguera y movilidad reducida dentro del Programa de Rehabilitación de la ONCE. RED Visual: Revista Especializada en Discapacidad Visual, 76, 91-114. https://doi.org/10.53094/IXVR2685. 


\section{Resultados}

Con la última adaptación del material expuesta anteriormente, Lucía ha conseguido la autonomía deseada, realizando sus desplazamientos seguros y siendo capaz de salvar los posibles obstáculos que se pudiera encontrar en el camino. Autónoma en recorridos conocidos, cercanos... Puede ir sola al centro de salud, al hospital, a casa de familiares, frecuenta sitios donde poder relacionarse con sus amistades, acude al supermercado...

A la hora de practicar recorridos con personas con discapacidad visual siempre hay que estar alerta de cuál es el más seguro, que a veces coincide con el más corto y a veces no. Hay ocasiones en las que la seguridad del usuario obliga a cambiar sus caminos habituales por otros, desconocidos, pero en un entorno más favorecedor, con mejores referencias, densidad de población, tráfico... En este caso concreto, el desplazamiento en silla de ruedas condicionó aún más la búsqueda de itinerarios idóneos, evitando en todo momento la existencia de situaciones de peligro o dificultad, teniendo en cuenta todas sus discapacidades. Todo ello supuso un esfuerzo añadido sin poder, en varias ocasiones, hacer uso del recuerdo visual que tan imprescindible es para orientarse. Además, había que añadir el tiempo que llevaba sin salir sola a la calle, sin conocer los cambios que se habían producido en ella. A pesar de ser en un entorno relativamente cercano, varias zonas tuvieron que ser tratadas como nuevas o desconocidas.

Figura 7. La afiliada desplazándose por el interior de un supermercado con su nuevo auxiliar de movilidad

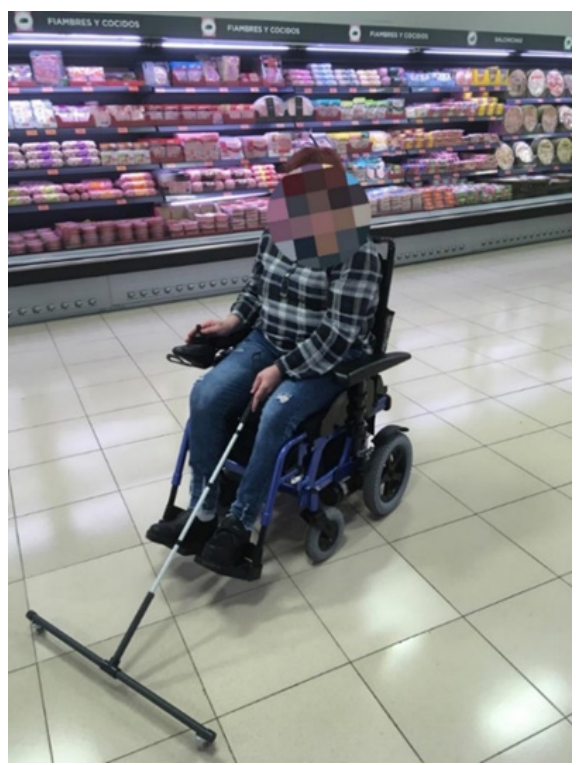

Galván, E. (2020). Adaptación del bastón de movilidad en un caso de sordoceguera y movilidad reducida dentro del Programa de Rehabilitación de la ONCE. RED Visual: Revista Especializada en Discapacidad Visual, 76, 91-114. https://doi.org/10.53094/IXVR2685. 
Poco a poco, y tal y como se ha ido evolucionando en este proyecto, el resultado final ha sido la consecución del objetivo que se propuso desde un principio: conseguir la autonomía de Lucía.

En otros casos, con ceguera total o en situaciones de entornos mucho más problemáticos y complicados en lo referente a las aceras, tal vez hubiera sido posible investigar si el añadir a mitad de la barra paralela al suelo un sensor que detectara pequeños desniveles, agujeros, que pudieran «colarse» entre rueda y rueda, sería aconsejable, aunque en este caso no ha sido necesario.

\section{Conclusiones}

«Luz para mis ojos, vida para mí». Esta frase fue un regalo que hizo Lucía al Servicio de Rehabilitación de la ONCE. Eso significa ahora la libertad para ella. Cuando se puso en contacto de nuevo y comunicó que había buscado un nombre para su nuevo auxiliar de movilidad y que ese nombre era Libertad, hizo que este proyecto tuviera más sentido aún. Y que Libertad supusiera la luz en sus ojos y la vida que no había podido tener antes de forma autónoma... eso recompensaba cualquier esfuerzo por muy grande que hubiera podido ser.

Lucía ha avanzado y evolucionado infinitamente mejor de lo que se podía esperar. Ha supuesto un aprendizaje de positivismo, ganas de vivir $y$, sobre todo, de esfuerzo de superación, siempre sin olvidar las limitaciones que su situación le impone.

Se debe intentar todo, ¿qué se puede perder? Probablemente, nada. Pero ¿y por no hacerlo? Si no nos tiramos a la piscina y probamos, por muy costoso y difícil que parezca lo que queramos, no tendremos ninguna posibilidad de conseguirlo. Por muy pequeña que sea esa posibilidad, siempre que pensemos que la hay, hay que jugar. Como se decía al principio, hay que saltar.

Desde el principio ha podido ser constatada la eficacia en la autonomía del trabajo realizado, mediante informaciones recibidas de su familia, gracias a vídeos grabados durante sus desplazamientos totalmente autónomos... todo ello transmitiendo ese afán de superación, de alegría de nuevo en la vida, acompañada de Libertad, nombre con el que se refiere a su ayuda de movilidad. Por momentos así, vale la pena cualquier esfuerzo. 
Por muy lejos que esté la demanda del servicio y por muy difícil que parezca de cumplir, siempre hay que intentarlo. Escuchar a la persona que solicita, ver su situación, analizar los factores por los que no ha salido, tratar de dar respuesta, pensar y ofrecer alternativas... Habrá casos en los que desgraciadamente no se pueda mejorar la autonomía de un afiliado o afiliada... pero no será por no intentarlo.

«El $90 \%$ del éxito se basa simplemente en insistir», Woody Allen

Elvira Galván González. Técnica de Rehabilitación. DAP de la ONCE en Huelva (Delegación Territorial de la ONCE en Andalucía). Alameda Sundheim, 5; 21003 Huelva (España). Correo electrónico: elgg@once.es. 


\section{Apéndice \\ Proceso de desarrollo del material}

En este apartado se explican detalladamente tres aspectos:

- Componentes del auxiliar de movilidad (materiales).

- Proceso de fabricación del mismo paso a paso.

- Cómo engancharlo al bastón una vez esté listo para usar.

\section{Componentes}

Los componentes que hacen falta para la construcción del auxiliar de movilidad son los siguientes:

- Un cáncamo pequeño con sus dos tuercas correspondientes (se ha de pedir en la ferretería que abran el cáncamo un poco para enganchar de él finalmente la goma del bastón).

- Dos tubos de PVC de $20 \mathrm{~mm}$ de diámetro y de $35 \mathrm{~cm}$ de largo.

- Un tubo de PVC de $20 \mathrm{~mm}$ de diámetro y de $15 \mathrm{~cm}$, aproximadamente, de largo.

- Dos tapones de PVC para uno de los extremos de los dos tubos largos.

- Una T para unir los diferentes tubos.

- Una chapa alargada con agujeritos que quepa dentro de esa T y en la que colocaremos el cáncamo.

- Dos ruedas giratorias pequeñas.

- Dos tornillos con sus respectivas arandelas y tuercas (para las ruedas).

- Pegamento para PVC. 
Se muestran a continuación fotos de los distintos componentes para mayor aclaración (Figuras 8 y 9).

Figura 8. Cáncamos y tubos de PVC
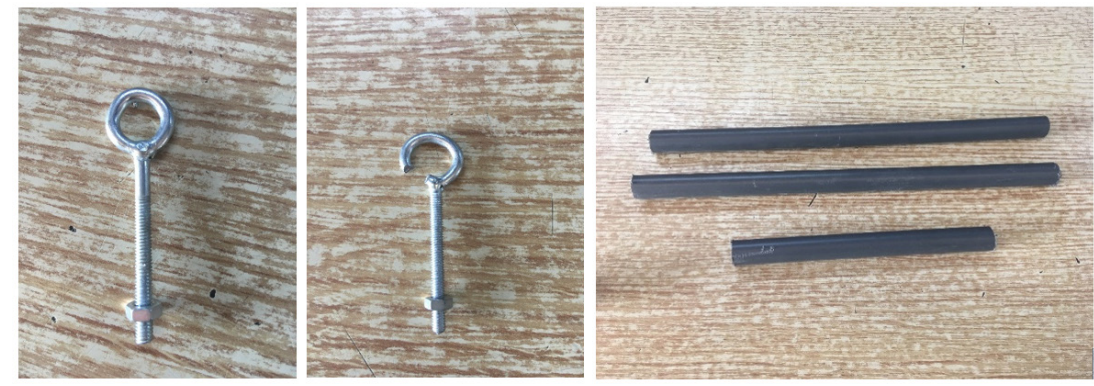

Figura 9. Tapones y T de PVC, chapa alargada, rueda giratoria, tornillos, arandelas y pegamento empleado
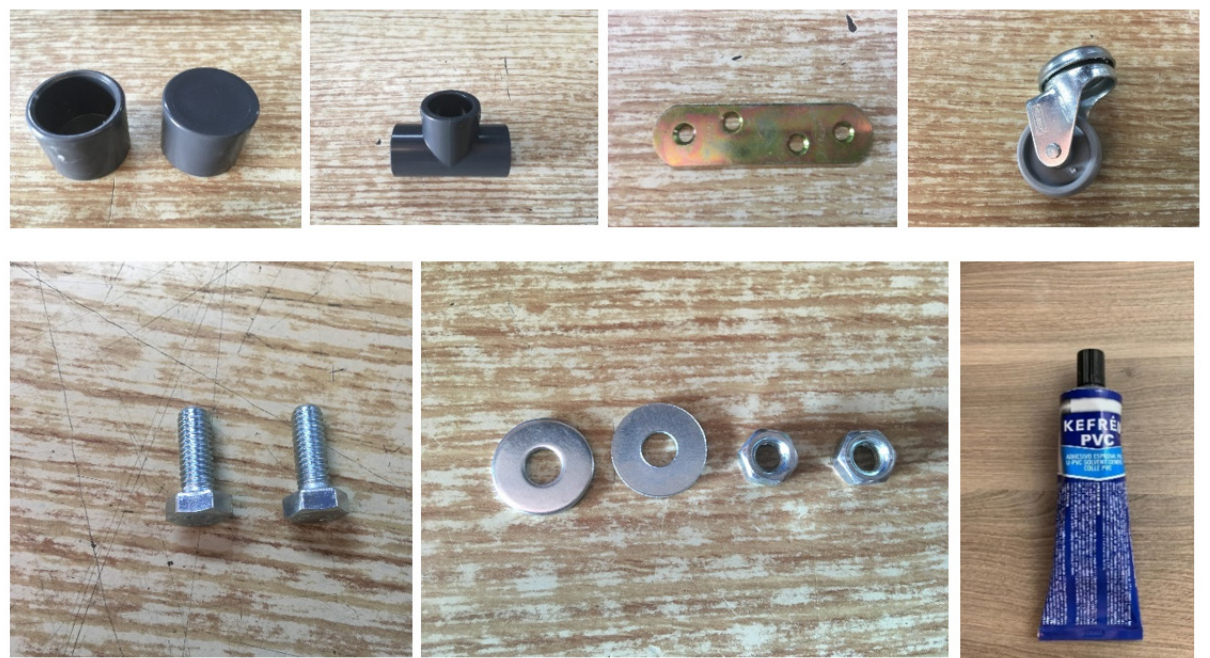

\section{Proceso de construcción}

A continuación, se expone, lo más detalladamente posible, el proceso de montaje del material utilizado en este proyecto.

1. Primero, se coloca el cáncamo en la $T$ de $P V C$, del cual se enganchará el bastón a la hora de utilizarlo.

Para ello, se necesita la T de PVC, el cáncamo, dos tuercas y la chapa.

Galván, E. (2020). Adaptación del bastón de movilidad en un caso de sordoceguera y movilidad reducida dentro del Programa de Rehabilitación de la ONCE. RED Visual: Revista Especializada en Discapacidad Visual, 76, 91-114. https://doi.org/10.53094/IXVR2685. 
El cáncamo tiene que estar ya abierto, debiendo prestar atención al limado correcto para que quede suave y no dañe la goma del bastón con el roce al colocarla.

Se introduce la chapa en el tubo de forma horizontal y desde arriba se mete el cáncamo con una tuerca ya puesta, quedando la parte redonda del cáncamo arriba. Quedaría entonces la chapa en medio y el cáncamo atravesando en vertical uno de sus agujeros. A continuación, se necesitan unos alicates pequeños y paciencia, porque lo que debe hacerse es un trabajo manual de precisión. Hay que coger con los alicates la tuerca y enroscarla poco a poco a la parte de abajo del cáncamo (trabajando por dentro del tubo de la T), hasta que quede fijo el cáncamo a la chapa. De esa forma, cuando se enganche la goma del bastón al cáncamo, no habrá posibilidad de que se suelte mientras se utiliza.

En la Figura 10 se observa cómo queda finalmente.

Figura 10. T de PVC con el cáncamo colocado
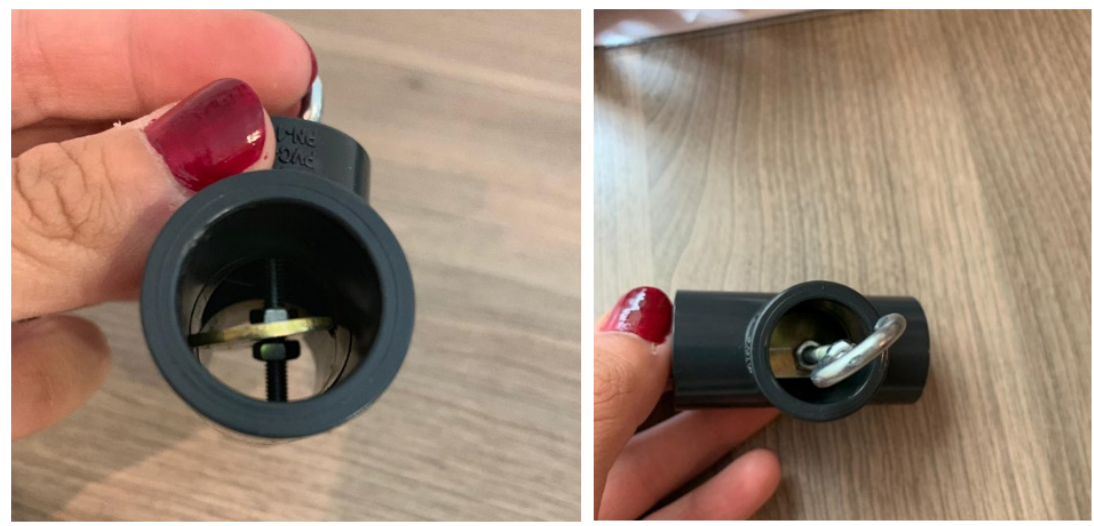

Una vez lista la T de PVC, se pasa a la siguiente fase del proceso.

2. Se lleva a cabo la realización de los agujeros donde irán colocadas las ruedas en los tubos de PVC. Este paso se realizará en un tubo y posteriormente en el otro.

Se coloca un tapón en un extremo de uno de los tubos de PVC de $35 \mathrm{~cm}$. El tapón se sobrepone sin pegar, ya que solo se requiere para medir. Una vez se tiene el tubo con un tapón puesto, en ese extremo y muy cerca se sujeta la base de una rueda y se hace en el agujero que queda libre una marca para saber dónde habrá que taladrar posteriormente. 
Ahora ya se puede quitar el tapón y realizar la apertura con un taladro. El agujero quedaría como se muestra la figura 11.

Figura 11. Tubo de PVC con el agujero realizado para la consiguiente colocación de la rueda

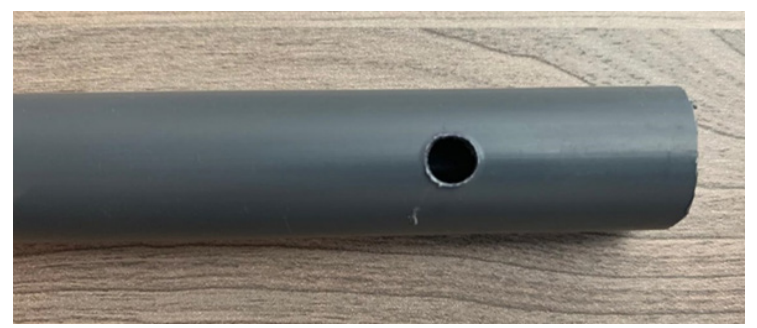

Se repite el mismo procedimiento con el otro tubo para tener finalmente los dos tubos de $35 \mathrm{~cm}$ con su agujero correspondiente.

3. El siguiente paso es colocar las ruedas. Igual que en el apartado anterior, se procede a la explicación de la colocación de una rueda y se aplica lo mismo para la otra.

Se necesita un tornillo, una arandela y la rueda. Puesta la rueda de pie, se introduce el tornillo al revés (de abajo hacia arriba).

Quedará sobresaliendo por la parte de arriba la parte alargada del tornillo, la cual se procede a introducir por el agujero del tubo de PVC (Figura 12).

Figura 12. Imágenes del tubo sujetando la rueda dentro del mismo
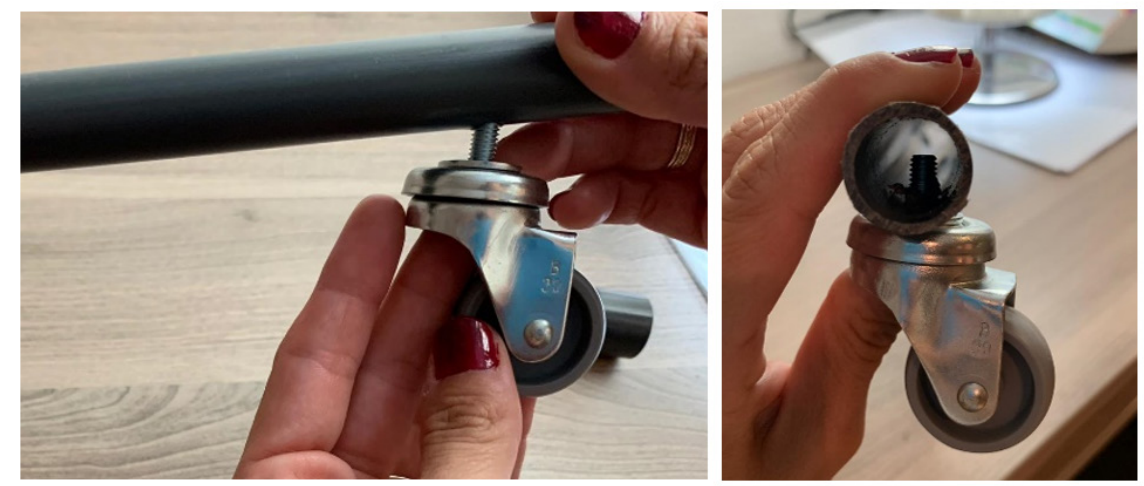

A continuación, haciendo uso de un alicate, se aprieta el tornillo por dentro (se trabaja de nuevo por dentro del tubo). Quedaría, ya colocada la rueda, tal y como se puede observar en la Figura 13.

Galván, E. (2020). Adaptación del bastón de movilidad en un caso de sordoceguera y movilidad reducida dentro del Programa de Rehabilitación de la ONCE. RED Visual: Revista Especializada en Discapacidad Visual, 76, 91-114. https://doi.org/10.53094/IXVR2685. 
Figura 13. Rueda colocada dentro del tubo

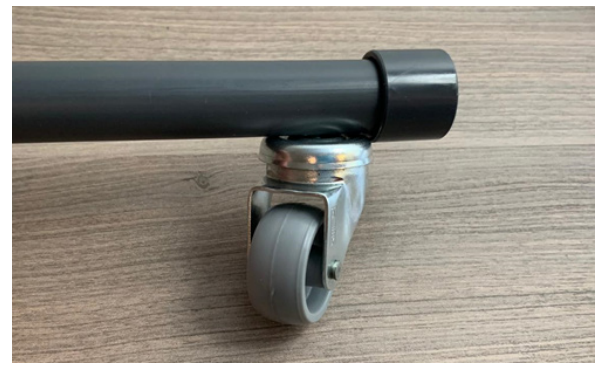

Ahora se repiten los mismos pasos para poner la rueda en un extremo del otro tubo.

4. Ya se encuentra la T con su cáncamo colocado y los dos tubos largos de PVC con las ruedas atornilladas. Ahora hay que unirlo todo para terminarlo.

Lo primero que se hace es unir (sin pegar aún) todos los elementos. Se meten en la $\mathrm{T}$ los dos tubos largos, uno a cada lado, y se engancha el bastón al cáncamo metiendo también el tubo más corto de PVC por arriba.

De esta forma, y aunque sin pegar aún, quedaría a simple vista lo que será el utensilio final.

¿Y por qué no se pega aún? Porque hay que darle la inclinación adecuada. En este caso, es la inclinación de la silla, de forma que al sentarse en la silla se van girando los tubos hasta que el desplazamiento sea correcto y se vea que giran adecuadamente desde la posición de sentado.

Cuando ya se tenga fijada la inclinación deseada, se hace una marca para no perder la referencia al quitarlo para untar el pegamento, como se ve en la Figura 14.

Figura 14. Tubo con las marcas para el pegado final

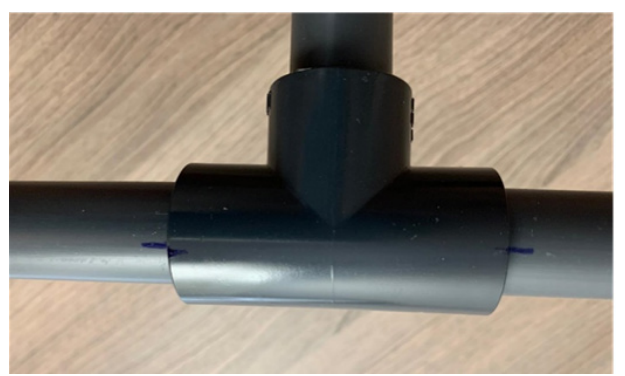

Galván, E. (2020). Adaptación del bastón de movilidad en un caso de sordoceguera y movilidad reducida dentro del Programa de Rehabilitación de la ONCE. RED Visual: Revista Especializada en Discapacidad Visual, 76, 91-114. https://doi.org/10.53094/IXVR2685. 
Una vez marcados, se quitan los dos tubos largos, se pone el pegamento y se pega haciendo coincidir las marcas. A continuación se procede al pegado de los tapones (uno a cada extremo, al lado de cada rueda).

El tubo corto no se pega, ya que no se podría meter en un futuro el bastón o cambiarlo cuando fuera preciso.

El tubo corto se utiliza porque la primera vez que se hizo el aparato se observó que la goma del bastón colocada en el cáncamo no se quedaba rígida, de forma que, al caminar con el aparato, bailaba el bastón de un lado a otro. Entonces se pensó que había que ponerle un tubo vertical para darle rigidez y que fuera funcional. Así, si el bastón se movía, la afiliada no lo notaría, ya que ese tubo impediría dicho movimiento.

Queda, pues el material de la siguiente manera (ver Figura 15).

Figura 15. Adaptador en forma de T acabado
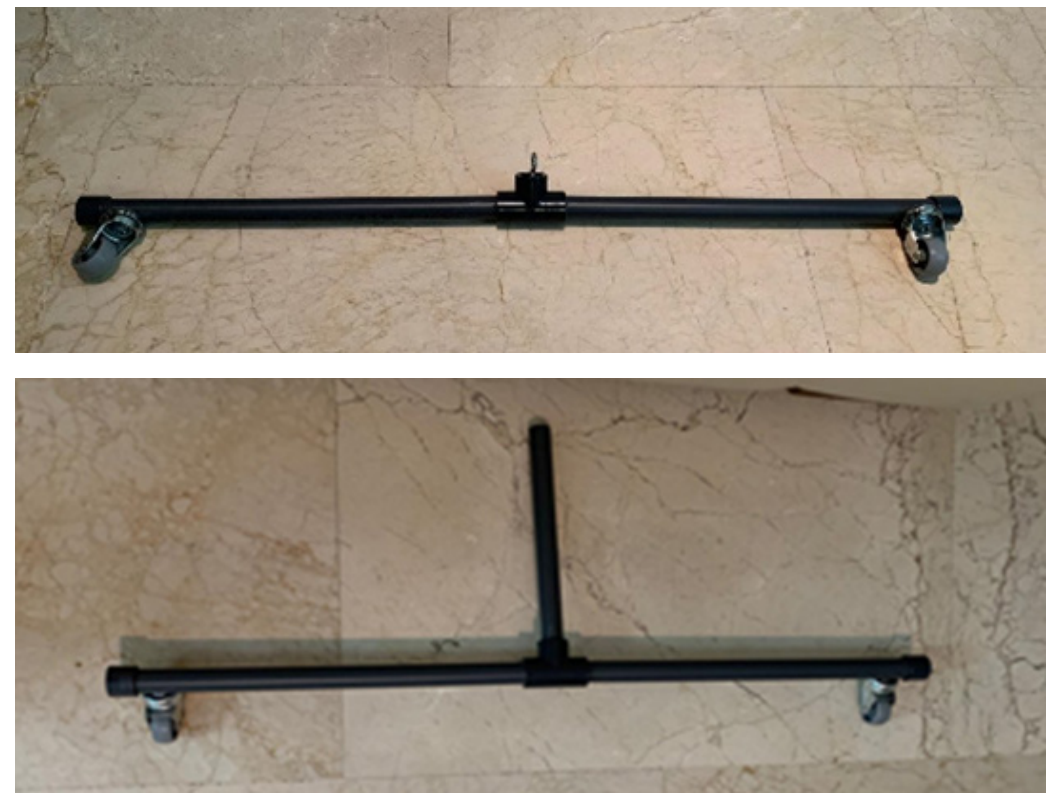

Una vez está el material terminado, se le puede poner cinta adhesiva blanca para que, a simple vista, recuerde más a un bastón de movilidad. Así, en vez de gris oscuro quedaría de color blanco y sería también más visible para las demás personas, no perdiendo nunca el adaptador, material o Libertad, como le llama Lucía, su característica de símbolo de la discapacidad visual. 


\section{Cómo enganchar el material al bastón una vez acabado}

Hay que quitar el tubo pequeño de PVC del adaptador para enganchar la goma del bastón. Se retira la contera del bastón y se estira la goma bastante. Esa goma se mete por un extremo del tubo pequeño de PVC y se coge por el otro extremo de dicho tubo cuando salga. Ahora se engancha la goma al cáncamo para que quede sujeta al material. Finalmente, como el tubo pequeño no quedará fijado al instrumento, es necesario unirlo a la T de PVC para que quede sujeto y no haya movimientos incómodos cuando se produzca el desplazamiento en los recorridos.

Es muy importante en todo este proceso tener cuidado de que no se nos escape la goma del bastón, ya que luego su colocación, si se nos va, es muy difícil. En definitiva, proceder con el mismo o mayor cuidado que al cambiar una contera.

Figura 16. Imagen final del adaptador enganchado al bastón de movilidad

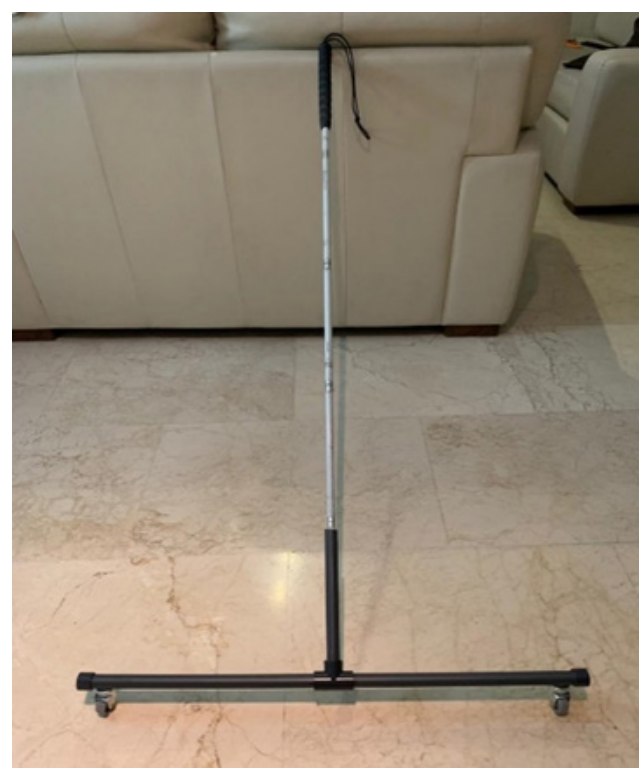

Finalmente, se colocaron pegatinas rojas, a petición de ella, para que fuera símbolo de sordoceguera y no únicamente de discapacidad visual. 